\title{
Effect of Time and Steam Pressure on Gelatinization of Starch and Antioxidant Properties of Curcumin of Turmeric (Curcuma Longa) Rhizomes
}

\author{
Wasiya Farzana ${ }^{1 *}$, Ashitha G. N. ${ }^{1}$, Eresh Kumar Kuruba ${ }^{2}$ and D. Amirtham ${ }^{1}$ \\ ${ }^{1}$ Tamil Nadu Agriculture University, Coimbatore, Tamil Nadu (641 003), India \\ 2Jawahar Nehru Krishi VishwaVidyalaya, Jabalpur (482 004), India
}

\author{
Corresponding Author \\ Wasiya Farzana \\ e-mail:wasee92@gmail.com
}

\author{
Article History \\ Article ID: IJEP0238 \\ Received in $29^{\text {th }}$ October, 2017 \\ Received in revised form $4^{\text {th }}$ February, 2018 \\ Accepted in final form $10^{\text {th }}$ February, 2018
}

\begin{abstract}
Turmeric grown in state of Tamil Nadu in India was analysed for its change in Curcumin content when subjected to varying pressures of steam during pressurised steam boiling under laboratory scale conditions. The same were tested in the field for optimized conditions in the already existing turmeric boiling system with the farmers, the locally available parboiling drum used for paddy parboiling and the improved steam boiling vessel developed at Tamil Nadu Agricultural University.The varying pressures which brought about varying degrees of gelatinization of starch which in turn affecting the Curcumin content were studied. Consequently the bioavailability of Curcumin and its antioxidant properties were analysed considering its health benefits. The best quality of turmeric in terms of Curcumin content was obtained at $46.43 \%$ degree of starch gelatinization. The highest RSA (24\%) was obtained at 5 minutes at $5 \mathrm{~kg} \mathrm{~cm}^{-2}$ pressure treatment. The correlation between degree of starch gelatinization and antioxidant property of turmeric was found to be highly negative (-0.9577).
\end{abstract}

Keywords: Turmeric, curcumin content, pressures, boiling, steam, gelatinization

\section{Introduction}

Turmeric being a crop majorly produced in India having a monopoly over export market with $82 \%$ is valued for its Curcumin content, a major parameter upon which the quality is based. Curcumin, a polyphenol is the active substance of turmeric and curcumin is known as C.I. 75300 or Natural Yellow 3. It is used in canned beverages and baked products, dairy products, ice cream, yogurt, yellow cakes, orange juice, biscuits, popcorn colour, sweets, cake icings, cereals, sauces, gelatins, etc. (USDA-GRIN, 2008). It is also used in textile industry, in thepreparation of oils, ointments and poultice, in cosmetic product to prepare natural and herbal creams, lotion and hair dye (Shinde et al., 2011). Turmeric isextensively used in Ayurveda, Unani and Siddha medicines as home remedy for various diseases. In old Hindu medicine, it is extensively used for the treatment of sprains and swelling caused by injury. Several studies have dealt with the pharmacological effects of turmericcomponents (Araujo and Leon, 2001): antioxidant (Quiles et al., 2002), anti-inflammatory (Surh, 2002), antimutagenic (Inano and Onada, 2002), anticarcinogenic (Kim et al., 2000), antimicrobial (Negi et al., 1999) and antivenom (Ferreira et al., 1992). It is used as a food additive (spice), preservative and colouring agent in Asian countries, including China and South East Asia. The bright yellow colour of turmeric comes mainly from fat- soluble, polyphenolic pigments called curcuminoids which has curcumin as its principal component. Turmeric contains a wide variety of phytochemicals including curcumin, demethoxycurcumin, bisdemethoxycurcumin, zingiberene, curcumenol, curcumol, eugenol, tetrehydrocurcumin, triethylcurcumin, turmerin, turmerones and turmeronols (Chattopadhyay et al., 2004). The structure of curcumin $\left(\mathrm{C}_{21} \mathrm{H}_{20} \mathrm{O}_{6}\right)$ was first described in 1910 by Lampe and Milobedeska (Himesh et al., 2011).

Curcumin has antioxidant, anti-inflammatory, antiviral and antifungal actions.

Though there are many boiling systems used by the farmers to process turmeric, they are found to be inefficient, time consuming, laborious and costly. Pressurised steam boiling being the most advanced method of boiling turmeric has an impact over its curcumin content, moisture content, oleoresin, essential oils, hardness with variable pressures. Among these curcumin content is the deciding factor and hence taken for the study.The variety, type of boiler and dryer are also the important parameters which affect the curcumin content in turmeric.

In India turmeric is grown in an area of $1,04,500$ ha producing 
annually 4,30,000 t (2012-13). Although, India is leading in its production (75\% of world output), the average productivity and quality are not satisfactory and these limit our export to about 10 to $15 \%$ of our production only. However, annually 18 to 20 crore worth of turmeric are exported. The major turmeric growing states in India are Andhra Pradesh, Tamil Nadu, Maharashtra, Assam, Kerala, Karnataka and West Bengal in which Andhra Pradesh $160 \%$ of total turmeric production in India) is the leading producer state followed by Tamil Nadu (13\%), Karnataka and Maharashtra.

Boiling or curing of turmeric which is one of the steps which decides the final Curcumin content present in the product. Blanching (boiling in water for a set period of time) is carried out to facilitate the drying process of the rhizomes, to allow the starch granules to gelatinize and to inactivate enzymes (Plotto, 2004; Panda, 2010). The quality of final curcumin is greatly affected by small change in steam pressure and time. The main aim of the study was to reach the optimum degree of gelatinization at which there exists highest bioavailability of curcumin which influences the antioxidant properties of the turmeric. The commodities having antioxidant properties are incorporated in the neutraceuticals for having health benefits.

\section{Materials and Methods}

\subsection{Material}

\subsubsection{Sample preparation}

Turmeric variety PTS 10 (hybrid) grown locally in Erode district of Tamil Nadu was procured and stored under dry, dark and cool conditions.

This research was conducted in the 2015-16 in the Department of Agricultural Process and Food Engineering of Tamil Nadu Agricultural University Coimbatore.

\subsection{Methodology}

\subsubsection{Determination of degree of starch gelatinization}

Determination of gelatinised starch using Glucoamylase and o-Toluidineas described by B. Y. Chiang; J. A. Johnson was followed for determining the degree of starch gelatinization in turmeric. This method is widely applicable for starch solutions having low quantities of low-molecular weight oligosaccharides like glucose, sucrose and raffinose. (Chiang and Johnson, 1976)

2.2.1.1. Reagents used for determining gelatinized starch contents

o-Toluidine Reagent. Dissolved $1.5 \mathrm{~g}$ thiourea in $940 \mathrm{ml}$ of glacial acetic acid and then adding $60 \mathrm{ml}$ of o-toluidine. This solution was stored in an amber bottle.

Sodium Acetate Buffer. Dissolved $4.1 \mathrm{~g}$ of anhydrous sodium acetate in 1 litre distilled water and adjusted $\mathrm{pH}$ to 4.5 with acetic acid.
Glucoamylase Solution. Dispersed 2g Rhizopusglycoamylase in 250 mlof acetate bufferand filtered rapidly through glass fibre paper. To be used within 2 h.Specific activity of glucomaylase was 1:2000 $\mathrm{mmol}$ glucose formed $\mathrm{min}^{-1} \mathrm{mg}^{-1}$ protein at $\mathrm{pH}$ 5.5-6.0 and $40{ }^{\circ} \mathrm{C}$

\subsubsection{Procedure}

a. Preparing Sample with Partially Gelatinized Starch. Dispersed $20 \mathrm{mg}$ of sample in $5 \mathrm{ml}$ of distilled water in a 50 $\mathrm{ml}$ centrifuge tube.

b. Preparing Sample with totally Gelatinized Starch. Dispersed $20 \mathrm{mg}$ of sample in $3 \mathrm{ml}$ of distilled water and $1 \mathrm{ml}$ of $1 \mathrm{~N} \mathrm{NaOH}$ contained in a $50 \mathrm{ml}$ centrifuge tube. After five minutes $1 \mathrm{ml}$ of $1 \mathrm{~N} \mathrm{HCl}$ was added

c. Glycoamylase digestion and glucose determination. Added $25 \mathrm{ml}$ glucoamylase solution to each tube and incubated for $30 \mathrm{~min}$ at $40{ }^{\circ} \mathrm{C}$. Added $2 \mathrm{ml} \mathrm{25 \%}$ trichloroacetic acid (TCA) to inactivate glucoamylase (and to precipitate it in other proteins) and centrifuged it at 16,000xg for 5 minutes. To $0.5 \mathrm{ml}$ of supernatant solution in test tubes, added $4.5 \mathrm{ml}$ of o-toluidine reagent. Placed testtubes in boiling water for 10 minutes, cooled with cold water and added $5 \mathrm{ml}$ of glacial acetic acid. Measurement of absorbance was taken at 630 $\mathrm{nm}$.

Gelatinized starch (\%) was calculated as follows:

Where $Y$ is the $\%$ of starch gelatinised

$A$ is absorbance of Total gelatinised starch

$B=$ the absorbance of mixture of partially gelatinized or intact starch after 30 min enzymatic hydrolysis

$\mathrm{C}=$ the absorbance of mixture of partially gelatinized or intact starch after 60 min enzymatic hydrolysis

$\mathrm{k}=$ the absorbance of $1 \%$ of intact starch digested in $30 \mathrm{~min}$ and constant for each variety and specially treated starch and needs to be determined only once in routine analysis.

\subsubsection{Determination of antioxidant properties of turmeric}

\section{Determination of antioxidant properties}

Antioxidant properties were determined using protocol described by Mathangi and Prabhakaran (2013)

\subsubsection{Processing of turmeric for extract preparation}

About $60 \mathrm{~g}$ of dry sample turmeric powder was weighed and macerated with $500 \mathrm{ml}$ of each solvent (hexane, ethyl acetate and methanol) separately and kept overnight in shaker. The extract was collected after filtration using Whatman No.1 filter paper and was stored. Another $75 \mathrm{ml}$ of solvent was added to the residual mixture and incubated in shaker for 24 hrand the extract was collected again using a Whatman No.1 filter paper. This procedure was repeated once again and the extract was evaporated below $40^{\circ} \mathrm{C}$, which was used for further phytochemical analyses.

\subsubsection{Procedure for free radical scavenging activity}


The ability of the extracts to annihilate the DPPH radical (1, 1-diphenil-2- picrylhydrazyl) was investigated by the method described by Blois (1958). Stock solution of the whole plant extracts was prepared to the concentration of $1 \mathrm{mg} \mathrm{ml}^{-1}$. $100 \mathrm{\mu g}$ of each extracts were added, at an equal volume, to methanolic solution of DPPH $(0.1 \mathrm{mM})$. The reaction mixture is incubated for $30 \mathrm{~min}$ at room temperature; the absorbance was recorded at $517 \mathrm{~nm}$. The experiment was repeated for three times. Ascorbic acid was used as standard controls.

\section{Results and Discussion}

\subsection{Degree of starch gelatinization for lab scale studies}

As shown in Figure 1 the trend for degree of starch gelatinization was found to increase with pressure and time. It was found to be highest (74.66\%) in the sample treated for $1.5 \mathrm{~kg} \mathrm{~cm}^{-2}$ pressure for 15 minutes. The increase in pressure leads to increase in

Varying Degree of starch gelatinization with pressure and time
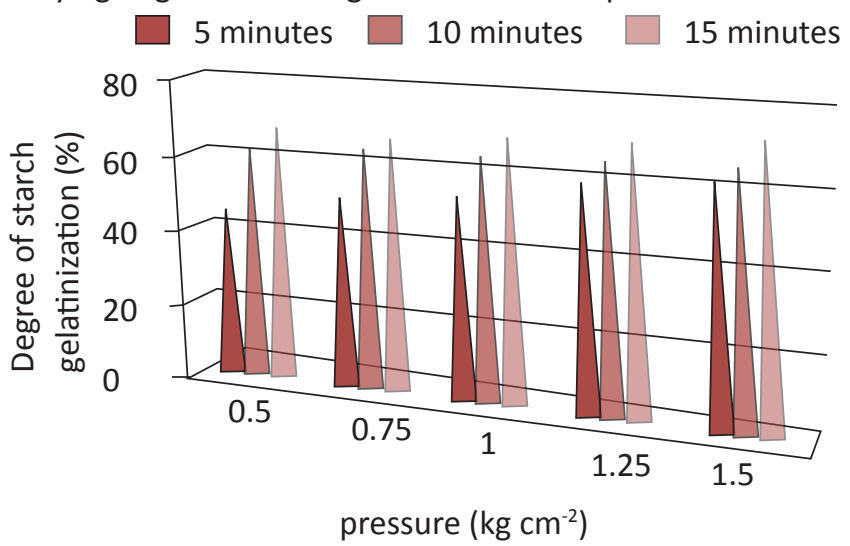

Figure 1: Varying degree of starch gelatinization with pressure and time

the heat energy given to the rhizomes and the time increment together increases the degree of starch gelatinization. While the lowest (46.43\%) was found to be with the treatment of $0.5 \mathrm{~kg}$ $\mathrm{cm}^{-2}$ for 5 minutes. The results are presented in Table 1.

\subsection{Degree of starch gelatinization for field studies}

As shown in Figure 2, the degree of starch gelatinization was found to reduce with improvements in boiling system. In the present study it was observed that the improved turmeric cooking vessel has the least starch gelatinization (\%) with a value of $49.46 \%$ followed by parboiling drum with $51.73 \%$ and then by open steaming $52.29 \%$. This may be due to larger time of cooking in open steaming with time being 15 minutes compared to parboiling drum having 10 minutes and improved vessel having 7 minutes of steaming. The results are presented in Table 2.

Leonel et al. (2003) have recorded $47 \%$ of starch content in C. longa and $57.7 \%$ in C. zedoaria. Kuttigounder et al. (2011) reported the starch yield as $56 \%$.

Dhivya (2015) reported that maximum starch content of 57.79
Table 1: Degree of starch gelatinization for lab scale studies

\begin{tabular}{lccc} 
SI. No. & $\begin{array}{c}\text { Pres- } \\
\text { sure }\end{array}$ & Duration & $\begin{array}{c}\text { Degree of starch } \\
\text { gelatinization \% }\end{array}$ \\
\hline 1. & 0.5 & 5 minutes & 46.43 \\
2. & 0.75 & & 51.84 \\
3. & 1 & & 54.72 \\
4. & 1.25 & & 60.93 \\
5. & 1.5 & & 63.21 \\
6. & 0.5 & 10 minutes & 64.02 \\
7. & 0.75 & & 65.11 \\
8. & 1 & & 65.34 \\
9. & 1.25 & & 66.48 \\
10. & 1.5 & & 68.22 \\
11. & 0.5 & 15 minutes & 68.43 \\
12. & 0.75 & & 68.51 \\
13. & 1 & & 70.84 \\
14. & 1.25 & & 71.52 \\
15. & 1.5 & & 74.66 \\
\hline
\end{tabular}

Degree of strach gelatinization

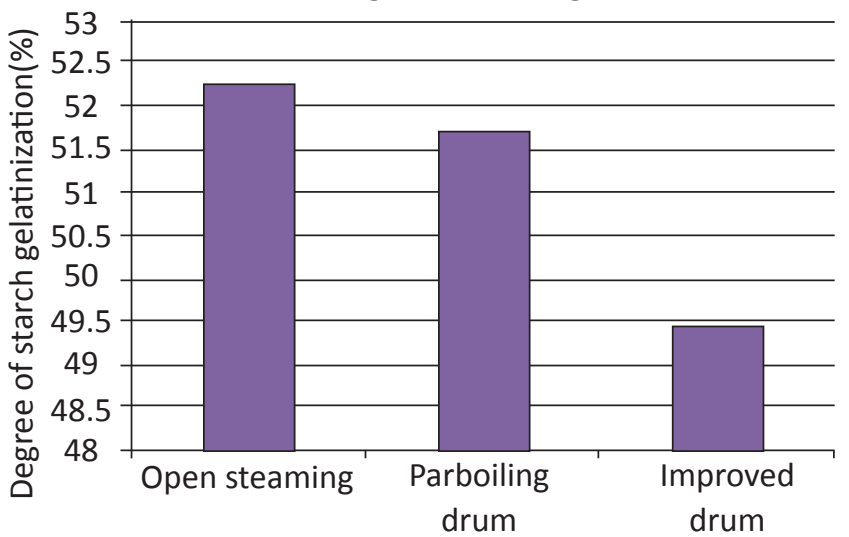

Figure 2: Varying degree of starch gelatinization for field studies

\begin{tabular}{|c|c|c|}
\hline SI no & $\begin{array}{l}\text { Different vessels for } \\
\text { boiling }\end{array}$ & $\begin{array}{l}\text { Degree of starch } \\
\text { gelatinization \% }\end{array}$ \\
\hline 1 & Open steaming & 52.29 \\
\hline 2 & Parboiling drum & 51.73 \\
\hline 3 & Improved drum & 49.46 \\
\hline
\end{tabular}

$\%$ was recorded by Erode finger samples and minimum of 56.68 $\%$ was recorded by Salem bulb samples.

\subsection{Antioxidant property of turmeric for laboratory studies}

The antioxidant property was found after giving different pressures and time combinations. RSA \% is presented in Table 
3. The highest value obtained was for $0.5 \mathrm{ksc}$ for 5 minutes (Figure 3). This can be explained that with increasing starch gelatinization the curcumin decreases. Curcumin content directly influences the level of radical scavenging property.

\begin{tabular}{|c|c|c|c|}
\hline $\begin{array}{l}\text { S I. } \\
\text { No. }\end{array}$ & Duration & Pressure & $\begin{array}{c}\text { Radical scavenging } \\
\text { activity (\%) }\end{array}$ \\
\hline 1. & 5 minutes & 0.5 & 24 \\
\hline 2. & & 0.75 & 21 \\
\hline 3. & & 1 & 20 \\
\hline 4. & & 1.25 & 19.4 \\
\hline 5. & & 1.5 & 19.2 \\
\hline 6. & 10 minutes & 0.5 & 18.7 \\
\hline 7. & & 0.75 & 18.1 \\
\hline 8. & & 1 & 17.4 \\
\hline 9. & & 1.25 & 17.2 \\
\hline 10. & & 1.5 & 16.7 \\
\hline 11. & 15 minutes & 0.5 & 15.17 \\
\hline 12. & & 0.75 & 15.01 \\
\hline 13. & & 1 & 14.27 \\
\hline 14. & & 1.25 & 14.1 \\
\hline 15. & & 1.5 & 13.4 \\
\hline
\end{tabular}

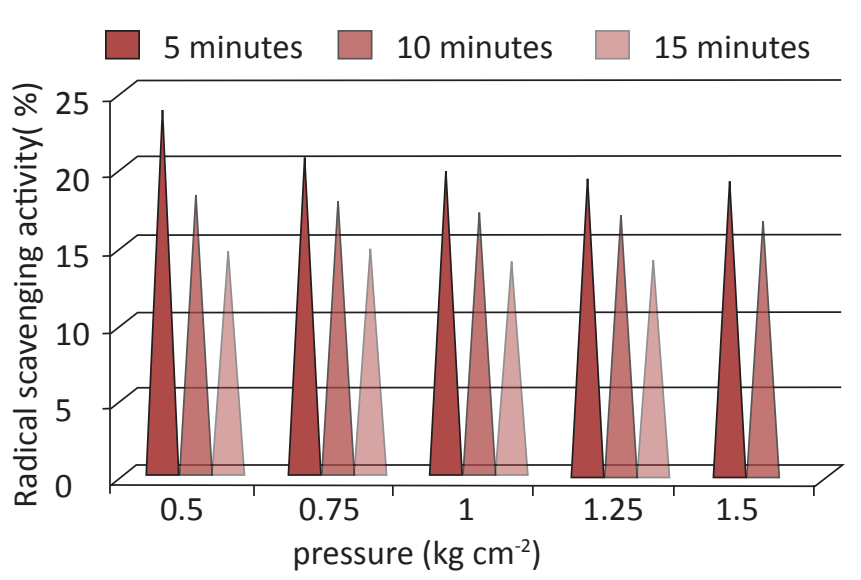

Figure 3: Varying degrees of antioxidant properties with pressure and time

\subsection{Antioxidant property of turmeric for field studies}

The colorant present in the turmeric which is curcumin has anti-oxidant property which was checked by DPPH method. The improved drum showed the highest value in the field trials having $\mathrm{RSA}=\mathbf{2 3 . 7 \%}$ and the least value was shown by open steaming having the value of $\mathrm{RSA}=15 \%$. This may be due to the fact that curcumin is heat sensitive as shown in Figure 4. The longer duration of cooking in open steaming leads to loss of curcumin, directly affecting the antioxidant property of turmeric. Results are presented in Table 4.

\begin{tabular}{|c|c|c|}
\hline $\begin{array}{l}\text { SI. } \\
\text { No. }\end{array}$ & $\begin{array}{l}\text { Different vessels for } \\
\text { boiling }\end{array}$ & $\begin{array}{c}\text { Radical scavenging } \\
\text { activity \% }\end{array}$ \\
\hline 1. & Open steaming & 15.08 \\
\hline 2. & Parboiling drum & 18.84 \\
\hline 3. & Improved drum & 23.7 \\
\hline
\end{tabular}

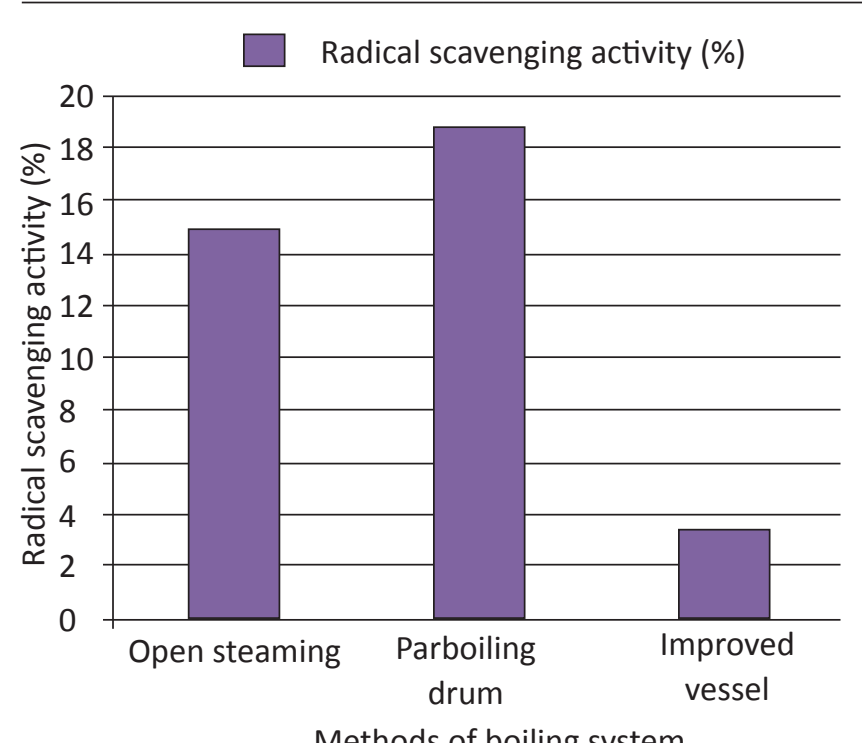

Methods of boiling system

Figure 4: Impact of methods of boing on Radical scavenging activity (\%) for field studies

\subsection{Correlation between degree of starch gelatinization and antioxidant properties}

The correlation between the degree of starch gelatinization and antioxidant properties for laboratory scale studies was found out. There exists a high negative correlation between the degree of starch gelatinization and the antioxidant properties with a value -0.9577 . This indicated that the RSA (\%) decreased as the degree of starch gelatinization increased.

\section{Conclusion}

The relation between degree of starch gelatinization and antioxidant property was found out with laboratory experiments and it was observed that with increasing degree of starch gelatinization the antioxidant property decreased. The same was observed to be true with the field studies. Statistically this relation was found to be the same.

\section{Acknowledgement}

The authors acknowledge the Tamil Nadu Agricultural University, Coimbatore for funding the project. The authors are also indebted to the Professor and Head, TNAU AEC\&RI Coimbatore campus for providing the requisite facilities for the work.

\section{References}

Araujo, C. C., Leon, L.L., 2001.Biological activities of Curcuma 
longa L. Mem Inst Oswaldo Cruz 96(5), 723-728.

Blois, M.S., 1958. Antioxidant Determinations by the Use of a Stable Free Radical. Nature 181, 1199-1200.

Chattopadhyay, I., Biswas, K., Bandyopadhyay, U., Banerjee, R.K., 2004. Turmeric and curcumin: Biological actions and medicinal applications. Current Science 87, 44-53.

Chiang, B.Y., Johnson, J.A., 1976. Measurement of Total and Gelatinized Starch by Glycoamylase and o-Touluidine Reagent. Cereal Chemistry 54(3), 429-435.

Dhivya K., 2015. Development of Rapid Grading Method for Quality Evaluation of Turmeric Rhizomes Using Ft-Nir Spectroscopy. M.Tech. theses Tamil Nadu Agricultural University, Coimbatore, TN, India.

Ferreira, L.A., Henriques, O.B., Andreoni, A.A., Vital, G.R., Campos, M.M., Habermehl, G.G., de Moraes, V.L., 1992. Antivenom and biological effects of ar-turmerone isolated from Curcuma longa (Zingiberaceae). Toxicon 30, 1211-8.

Himesh, S., Sharan, P.S., Mishra, K., Govind, N., Singhai, A.K., 2011. Qualitative and Quantitative Profile Of Curcumin From Ethanolic Extract Of Curcuma longa. International Research Journal of Pharmacy 2 (4), 180-184.

Inano, H., Onoda, M., 2002. Radioprotective action of curcumin extracted from Curcuma longa LINN: inhibitory effect on formation of urinary 8-hydroxy-2'- deoxyguanosine, tumorigenesis, but not mortality, induced by gamma-ray irradiation. International Journal of Radiation Oncology, Biology, Physics 53,735-743.

Kim, K.I., Kim, J.W., Hong, B.S., Shin, D.H., Cho, H.Y., Kim, H.K., Yang, H.C., 2000. Antitumor, genotoxicity and anticlastogenic activities of polysaccharide from Curcuma zedoaria. Mol Cell 10(4), 392-398.

Kuttigounder, D., Lingamallu, J.R., Bhattacharya, S., 2011. Turmeric Powder and Starch: Selected Physical, Physicochemical, and Microstructural Properties. Journal of Food Science 76(9), 1284-1291.

Lampe, V., Milobedeska, J., Kostanecki, V., 1910. Synthese von $p, p^{\prime}$ - dioxy-and p-oxy dicinnamoylmethchenchemischen Gesellschaft 43, 2163.

Leonel, M., Sarmento, S.B.S., Cereda, M.P., 2003. New starches for the food industry: Curcuma longa and Curcuma zedoaria.Carbohydrate Polymers 54(3), 385-388.

Negi, P.S., Jayaprakasha, G.K., Rao, L.J.M., Sakariah, K.K., 1999. Antibacterial activity of turmeric oil: a byproduct from curcumin manufacture. Journal of Agricultural and Food Chemistry 47, 4297-4300.

Mathangi, T., Prabhakaran, P., 2013. DPPH Free Radical Scavenging Activity of the Extracts of the Aquatic Fern, Marsilea quadrifolia Linn. International Journal of Current Microbiology and Applied Science 2(10), 534-536.

Panda, H., 2010. Handbook on Spices and Condiments (Cultivation, Processing and Extraction). Asia Pacific Business Press Inc., New Delhi, India, 22.

Plotto, A., 2004.Turmeric: Post-Production Management, Food and Agriculture Organization of the United Nations (FAO).

Quiles, J.L., Mesa, M.D., Ramirez-Tortosa, C.L., Aguilera, C.M., Battino, M., Gil, A., Ramirez-Tortosa, M.C., 2002. ArteriosclerThrombVasc Biology 22(7), 1225-1231.

Shinde, U.G., Kamble, K.J., Harkari, M.G., More, G.R., 2011. Process Optimization in Turmeric Heat Treatment by Design and Fabrication of Blancher. International Conference on Environmental and AgricultureEngineering IPCBEE vol.15, IACSIT Press, Singapore.

Surh, Y.J., 2002. Anti- tumour promoting potential of selected spice ingredients with anti-oxidative and inflammatory activities: a short review. Food Chemistry and Toxicology 40, 1091-1097.

USDA-GRIN, 2008. Curcuma longa information from NPGS/ GRIN.Available from http://www.ars-grin.gov/cgi-bin/ npgs/html/taxon.pl?12676. Accessed in November 2017. 